Çukurova Üniversitesi Mühendislik Mimarlık Fakültesi Dergisi, 30(2), 163-175 ss., Aralık 2015

Çukurova University Journal of the Faculty of Engineering and Architecture, 30(2), pp. 163-175, December 2015

\title{
Butik Otellerin Karakteristik Özelliklerinin Saptanması
}

\author{
Eda CAN $^{* 1}$, Onur ERMAN ${ }^{1}$ \\ ${ }^{1}$ Çukurova Üniversitesi, Mühendislik-Mimarlık Fakültesi, Mimarlık Bölümü, Adana
}

Geliş tarihi: 22.10.2015 Kabul tarihi:10.11.2015

\section{Özet}

Çalışma, dünyadaki turizm aktivitelerinde görülen gelişmelere paralel olarak ülkemizde de yaygınlaşan butik otelleri konu edinmektedir. Geniş bir yelpazeye yayılan hizmet çeşitliliği, çok farklı büyüklük ve hizmet kapasitesiyle birlikte her birinin kendine özgü nitelikte tasarıma sahip olması gibi nedenlerle butik oteller yıldızlı oteller gibi standardize edilememektedir. Bu durumun sonuçlarından biri literatürde butik otele ait kesin bir tanımın bulunmamasıdır. Bu nedenle bir konaklama yapısını butik otel olarak tanımlayan unsurların belirlenmesine ihtiyaç duyulmuştur. $\mathrm{Bu}$ amaçla butik otellere ilişkin tanımlama yaklaşımları tespit edilerek, bu yaklaşımlar ışığında butik otellerin özgün karakterinin biçimlenmesinde etkin olan ve "butik" olarak tanımlanmasını sağlayan kriterler saptanmaya çalışılmıştır. Konu alanında öncü çalışmaların taranmasıyla elde edilen bulgular 1şığında butik otellerin biçimlenmesinde etkin olan yedi karakteristik unsur belirlenerek tanımlanmıştır.

Anahtar Kelimeler: Butik otel, Tarihsel gelişim, Tanımlama yaklaşımları, Tanımlayıcı özellikler, Konaklama yapıları

\section{Determination of Characteristic Features of Boutique Hotels}

\begin{abstract}
The study focuses on boutique hotels which are grown up according to development of tourism activities in the worldwide and simultaneously in Turkey. Boutique hotels cannot be standardized as star hotels because of their different type of services, various size and capacity and also unique design styles. One of the consequences of this situation is lack of precise definition of boutique hotel in the literature. For this reason it is needed to determine the characteristics which define an accommodation building as a boutique hotel. The study aims to determine typical features of a boutique hotel with the help of descriptions and identifications found in the literature about the subject. In the light of these descriptive approaches, the criteria which have effects on formation of special characteristics of boutique hotels, and which help to describe an accommodation as "boutique" are tried to determine. According to results of literature review, seven primary characteristics which have influence on forming of boutique hotels were determined and identified.
\end{abstract}

Keywords: Boutique hotel, Historical development, Descriptive approaches, Descriptive features, Accommodation buildings

\footnotetext{
* Yazışmaların yapılacağı yazar: Eda CAN, Çukurova Üniversitesi, Mühendislik-Mimarlık Fakültesi, Mimarlık Bölümü, Adana,ecan@cu.edu.tr
} 


\section{GİRIŞ}

20. yüzyılın ikinci yarısından sonra ekonomik potansiyelinin keşfedilmesiyle turizm olgusu sektör halini almış ve turizm faaliyetleri artarak çeşitlenmiş̧ir. Turizmin gelişimini olumlu yönde tetikleyen faktörlerin; demografik yapı, politikalar ve ülkelerarası siyaset, sosyal ve kültürel yapı, ekonomi, teknoloji ve ekoloji olduğu söylenebilir. Özellikle ekonomik gelişmeler, kültürel ve ideolojik değişimler, çalışan nüfusun potansiyeli, sanayileşmiş toplumların sıkıntıları, çalışma ve dinlenme zamanları arasındaki ilişki bireyler için doğal ve kültürel çevreyi daha önemli hale getirmiş, tatil zamanlarının aktif değerlendirilmesinin önemini arttırmıştır. $\mathrm{Bu}$ gelişmeler 1şığında turistin beklentileri ve turistik faaliyetlere yönelik eğilimlerinde de değişimler görülmeye başlanmıştır [1]. $\mathrm{Bu}$ gelişmeler kaçınılmaz olarak konaklama yapılarının değişmesine ve çeşitlenmesine neden olmuştur. Son y1llarda dünyada gelişim gösteren ve buna paralel olarak ülkemizde de yaygınlaşan butik konaklama ve butik otel kavramı değişen turizm faaliyetleri içinde çeşitlenen konaklama yapıları arasında yer alır. Ancak çok yeni bir kavram olmasına rağmen hızla artış gösteren butik otel yapıları ve butik konaklama talebi konusunda yapılan çalışmaların oldukça sinırlı olduğu görülmektedir [2]. Otel yapılarına ve benzeri diğer konaklama yapılarına ilişkin pek çok sınıflama ve değerlendirme mevcutken, turizm kavramları içinde henüz yeni olan butik otel konusunda çalışmaların oldukça sınırlı oluşu bu konuda bir araştırma yapma gereğini ortaya çıkarmıştır. Çalışma butik oteli tanımlamada kullanılan kavramları inceleyerek, butik otel yapilarının karakteristik unsurlarını belirlemeyi hedeflemektedir. Böylelikle literatürde kesin bir tanımı bulunmayan ve otel gibi diğer konaklama yapilarında uygulanan siniflandırmaya tabi olmayan bu konaklama yapılarının özellikleri saptanarak, "butik otel nedir", "bir konaklama yapısının butik otel olarak tanımlanmasını sağlayan unsurlar nelerdir" sorularına yanıt verilmeye çalışılacaktır. Bu doğrultuda elde edilen sonuçların butik otel yapısının karakteristiğini ortaya çıkarması sonucunda butik otel tasarımına yön verecek unsurlara 1 ş̧1 tutabileceğ $\mathrm{i}$ düşünülmektedir.

\section{BUTIKK OTEL KAVRAMININ ORTAYA ÇIKIŞI}

Günümüzde değişen kullanıcı istekleri ve buna bağlı olarak farklılaşan turizm faaliyetleri doğal olarak konaklama tesislerinin çeşitlenmesine neden olmuştur. Standart konaklamanın dışında özel hizmet vererek farklı deneyimler sunan konaklama üniteleri bugün yıldızlı otel konaklamasina alternatif hale gelmiştir. İlk örnekleri 1980'lerde görülmekle beraber son yirmi yıldır popülerleşmeye başlayan butik oteller yeni tarz konaklama üniteleri arasında yükselen bir ivmeyle karşımıza çıkmaktadır.

Konaklama yapıları olarak oteller yüzyıllardır tasarıma ve yaşam tarzına yön vermiştir [3]. 19. yüzyılda sunulan iç mekan kalitesi, özelleşmiş ve özgün tasarım ürünleri otellerde kalite ve lüks unsuru olarak kullanılmış, yüksek yaşam standardının simgesi olmuştur. 20. yüzyılın ortalarına gelindiğinde ise Avrupa ve Amerika'da markalaşma eğilimi artmış, zincir oteller sektörde görülmeye başlamıştır. 1970'ler kıtalararası yayılan zincir otellerin zirvede olduğu dönemdir. Zincir otel olarak tanımlanan işletmelerin en önemli özelliği dünyanın neresinde olursa olsun; konaklanan odanın, alınan hizmetin tamamen aynı ve standart olmasıdır. Müş̧eri konaklama sırasında neyle karşılaşacağını önceden tam olarak bilir. Büyük bir otel zinciri bu tarz standardize edilmiş konaklamayı slogan haline getirerek "en iyi sürpriz sürprizin olmamasıdır" (the best surprise is no surprise) şeklinde reklamlarında kullanmıştır [3].

Butik konaklama sektörünün ortaya çıkışını ve hızla yayılma nedenlerini araştırmacılar iki farklı yöndeki görüşle açıklamaktadır. Aslında her iki görüş de birbirini destekler veya bir diğerinin oluşumunu açıklar niteliktedir. İlk görüşe göre; zincir otellerin yayılması, konaklamanın sistematik bir biçimde standartlaştırılması, müşterilerin karşı bir hareket olarak daha özgün ve yaratıcı karaktere sahip konaklama hizmetlerine yönelmesine neden olmuştur [4]. Günümüz gezgini artık sadece konforlu oda sunan bir otel yerine, kişinin imajına 
uyan, hikâyeye sahip otel aramaktadır [5]. Zincir otellerin yüksek derecede standartlaşmış konaklama hizmetine alternatif oluşturan butik oteller, ev ortamı atmosferi, kişiselleştirilmiş hizmet ve özgün tasarıma sahip olma kavramlarını kendine has unsurlar olarak öne çıkarmıştır [6].

Diğer görüş ise toplumların sosyal ve kültürel gelişimine dayandırılmaktadır. 1980'lerden itibaren gezginlerin ihtiyaçları, motivasyonları, talep ve beklentileri değişmiş, yeni gezgin grubu daha tatmin edici, kişisel yapısına zenginlik katan eğitici tatilleri talep etmeye başlamıştır. Çevre bilinci yüksek, daha duyarlı ve eğitimli bir gezgin grubu oluşmuştur ve bu grubun seyahatten beklentilerini karşılamada küçük konaklama tesisleri daha başarılıdır [7]. Bunlara ek olarak bireylerin konaklama tercihlerinin değişimi kültür, sanat ve tarihe olan ilginin artmasiyla ilişkilendirilir [8]. Bu küçük otellerin kendine özgü karakteriyle fazlaca seçeneğe sahip olması, yerel ve kültürel yaşamı deneyimlemeye imkân tanıması yeni gezgin kitlesi için tercih sebebi olarak görülmektedir.

Literatürde orijini 1980'lere dayandırılan butik otellerin ilk örneklerinin Londra'da 1981 yılında açılan Blake's Hotel, San Fransisco'da 1981 yılında açlan Bedford ve New York'ta 1984 yılında açılan Morgan's Hotel olduğu belirtilmektedir [3, 9, 10, 11, 12]. Butik otellerin öncü örneklerinin bir kısmı küçük Avrupa tarzı oteller olarak şekillenirken bir kısmı kullanıcıların konaklama deneyimlerini zenginleştirmek amaciyla özelleşmiş bir tema üzerinde biçimlenmiştir.

Konu ile ilgili ilk çalışmalarda butik otellerin "şehir evi oteli" (town house hotel) olarak adlandırıldığ olmadığı, Fransa'daki örneklerin "cazibe oteli" (hotel du charme), Schrager'in Morgan's Hotel tanımlarken ilk kez "butik" kavramını kullanmasıyla Amerika'dakilerin "butik otel" olarak tanımlandığı, yanı sıra ilk butik otel örneklerinin marka anlamında bir ismi dahi olmadığı, sadece adrese dayalı bir tarifleme yapıldığı ifade edilir [9]. Tasarım otel (design hotel), hip otel (hip hotel) ve yaşam tarzı otel (lifestyle hotel) kavramlari; tasarım kültürüne, özgün karaktere, şık ve zarif atmosfere, küçük ve bağımsız işletme yapısına sahip olan konaklama ünitelerini ifade ettikleri için sıklıkla butik otel ile özdeşleştirilir ve aynı anlamda kullanılır [3, 13, 14].

\section{BUTIKK OTELE İLIŞKIN TANIMLANMA YAKLAŞIMLARI}

Butik otellerin ilk örneğinin hangisi olduğu hakkındaki görüş çeşitliliği butik otelin tanımlanması konusunda karşımıza çıkmaktadır. Pek çok araştırmacı butik otelin kesin bir tanımının olmadiğından söz eder [6, 13, 15, 16]. Aggett (2007) İngiltere'de butik otel sayısının kesin olarak saptanamamasını butik otel konaklamasının açık bir tanımının yapılamamasına bağlar. Morrison ve diğerleri (1996) butik otel konaklamasının deneyime dayalı olmasının tanımlama yapmayı güçleştirdiğini belirtir. Ancak her ne kadar kesin bir tanımlama yapılmasa da literatürde pek çok tanımlama yaklaşımı bulunmaktadır. Araştırmacılar kendine has özellikleri nedeniyle standardize edilemeyen butik otelleri tanımlayabilmek için farklı yaklaşımlar geliştirmişlerdir. Bir kısmı işe "butik" kelimesini tanımlayarak ya da "neler butiktir" sorusuna cevap arayarak başlarken, bir kısmı butik otel ve butik konaklamaya ait özelliklerden yola çıkarak bir tanım oluşturmaya çalışmıştır [4, 10, 13, 17]. Kimi araştırmacılar ise butik konaklamayı sıradan bir otel konaklamasından ayıran özellikleri belirlemeye çalışarak tanım geliştirmek istemiştir $[7,18]$.

Literatürde yer alan tanımlama yaklaşımları bir araya getirildiğinde kapsamlı bir betimleme elde edilebilir. Buna göre butik oteller; özgün tasarımı ile zevk sahibidir, pek azı tasarımda alışılmadık tarzdadır ve çoğunluğu yenilenmiş, tarihi değeri olan yapılardır. Hizmet odağı daha çok yüksek gelir düzeyine sahip, 20-50 yaş aralığındaki kullanıcı kesimdir [10]. En yaygın özelliği "küçük olmak" olan bu oteller, her biri ayrı ayrı dekore edilmiş, Avrupa ya da Asya tarzı mobilyalarla döşenmiş yaklaşık 50-100 odaya sahiptir [9, 11]. Daha çok kent merkezinde yer alan, lüks ve kişiye 
özel hizmet sunan bu yapılar zincir işletmeye bağlı olmayıp genellikle sahibi tarafindan işletilir [3]. $\mathrm{Bu}$ bakımdan butik oteller; kişiselleştirilmiş ve unutulmaz bir deneyim yaşatan, misafirlerine evden uzakta, ev ve ötesi konforu sunan, tasarım temasına sahip, konaklayanlara anlatacak hikâyesi olan konaklama yapılarıdır [5, 19].

Ülkemizde ise butik oteller Turizm Tesislerinin Belgelendirilmesine ve Niteliklerine İlişkin Yönetmeliğin (2005/8948) 7. bölümü, 43. maddesinde özel tesisler başlığı altında ele alınarak, "yapısal özelliği, mimari tasarımı, tefriş, dekorasyon ve kullanılan malzemesi yönünden özgünlük arz eden, işletme ve servis yönünden üstün standart ve yüksek kalitede, deneyimli veya konusunda eğitimli personel ile kişiye özel hizmet verilen ve belirtilen nitelikleri taşıyan en az on odalı oteller" olarak tanımlanmıştır [20]. Yönetmeliğin devamında belirlenen nitelikler şu şekilde sıralanmaktadır:

a) Modern, reprodüksiyon, antika gibi özelliği olan mobilya ve malzemeler ile tefriş ve dekorasyon,
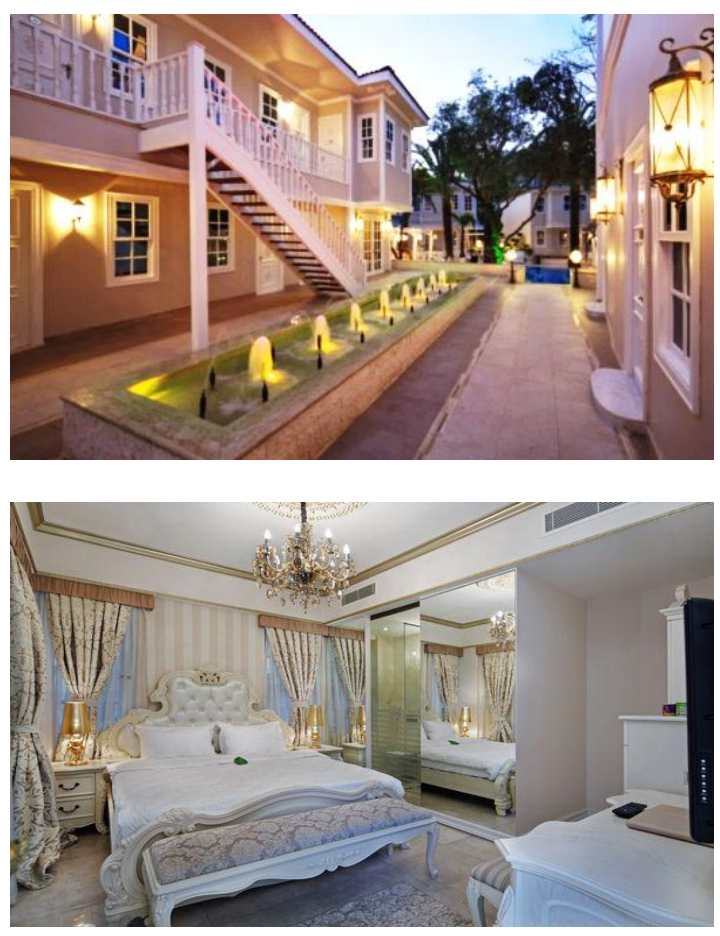

b) Beş yıldızlı otel odaları için belirlenen nitelikleri taşıyan konforlu odalar,

c) Yönetim odası,

d) Alakart lokanta,

e) Kapasiteye yeterli kabul holü, kahvaltı salonu, oturma salonu,

f) Genel mahallerde klima sistemi,

g) Yirmi dört saat oda servisi,

h) Çamaşır yıkama ve kuru temizleme hizmeti,

i) Otopark hizmeti,

j) Odalara, müşteri tarafından seçilen en az bir adet günlük gazete servisi.

Mevcut yönetmelik incelendiğinde mimari tarz, dekorasyon, hizmet niteliği, işletme yapısı ile büyüklüğü açısından (üst sınır verilmemekle birlikte) tanımlama yaklaşımları ile paralellik taşıdığı, bununla beraber belirlenen niteliklerle işletme bakımından butik otelleri standardize etmeye çalıştığ söylenebilir. Kültür ve Turizm Bakanlığının verilerine göre, butik otel işletme belgesine sahip 75 işletme, buna karşın, işletme belgesi olmamasına rağmen, butik hizmet veren çok daha fazla sayıda işletme olduğu tespit edilmiştir (Şekil 1) [2].
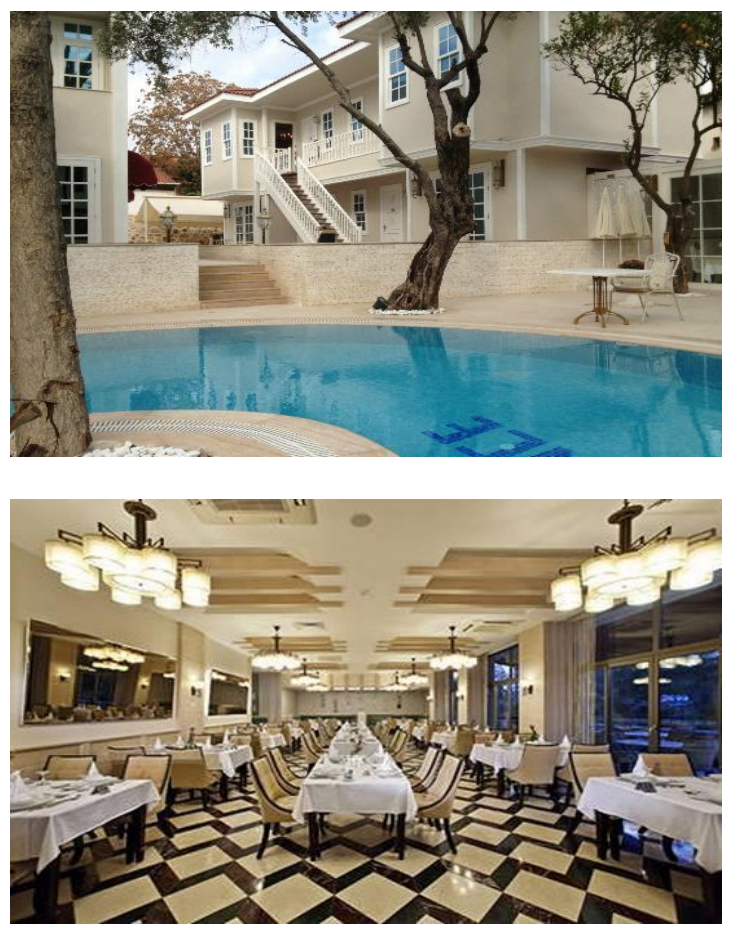

Şekil 1. Turizm Yönetmeliğine göre işletme belgesine sahip Antalya'dan bir butik otel örneği, (URL1) 
Çalışmanın bundan sonraki kısmında tanımlama yaklaşımları değerlendirilerek, butik otele ait tanımlayıcı karakteristik saptanmaya çalışılacaktır.

\section{BUTIKK OTEL KARAKTERİSTIGĞINI TANIMLAYAN UNSURLARIN SAPTANMASI}

İfade edilen tanımlama yaklaşımlarının çeşitliliği butik otelin kesin bir tanımını yapmanın güçlüğünün altını çizmektedir. Ancak tanımlama yaklaşımlarından elde edilecek ortak çıkarımlarla butik oteli şekillendiren karakteristik ögelerin tespit edilmesi olanaklıdır. Böylece butik oteli tanımlamaktan çok, butik oteli betimleyen ve nüvesini oluşturan karakteristiğin saptanması mümkün olacaktır. Standardize edilemeyen bu yapılar için daha geniş çerçevede ve daha esnek bir tanımlamanın bu şekilde elde edilebileceği düşünülmektedir. $\mathrm{Bu}$ amaçla butik otel konulu öncü ve konu alanına yön veren çalışmalar incelenerek, butik oteli tanımlamada kullanılan terimler tespit edilmiştir (Çizelge 1).

Çizelge 1. Tanımlama yaklaşımlarında kullanılan kavramlar ve literatür bilgisi

\begin{tabular}{|c|c|c|c|c|c|c|c|c|c|c|c|c|c|c|c|c|c|c|c|c|c|c|c|c|c|c|}
\hline & \multicolumn{13}{|c|}{ 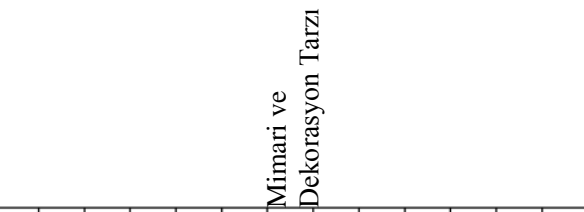 } & \multicolumn{3}{|c|}{ 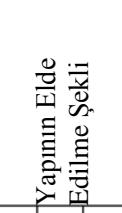 } & \multicolumn{3}{|c|}{ 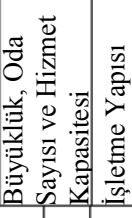 } & \multicolumn{2}{|c|}{ 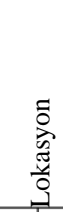 } & \multirow{2}{*}{ 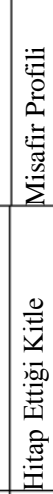 } & \multicolumn{4}{|c|}{ 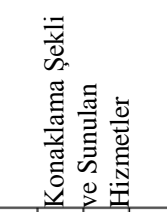 } \\
\hline & 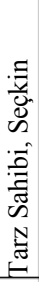 & 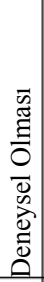 & 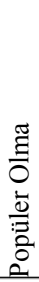 & 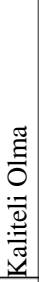 & 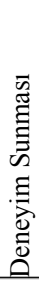 & 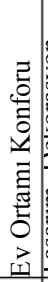 & 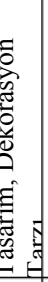 & 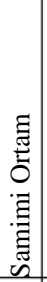 & 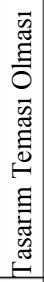 & 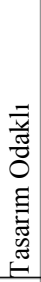 & 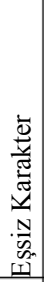 & 泀 & 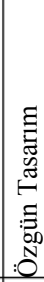 & 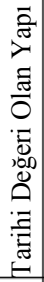 & 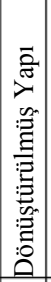 & 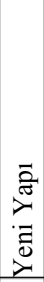 & $\begin{array}{l}\bar{n} \\
\sum_{\tilde{\pi}} \\
\tilde{D} \\
\tilde{n} \\
0\end{array}$ & 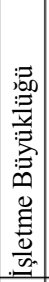 & 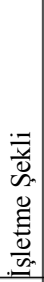 & 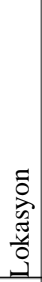 & 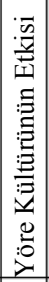 & & 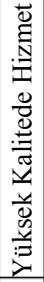 & 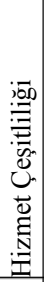 & 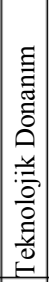 & $\begin{array}{l}\sum_{0}^{n} \\
\text { D } \\
0 \\
0 \\
0 \\
0 \\
0 \\
0\end{array}$ \\
\hline $\begin{array}{l}\text { Morrison ve diğ. } \\
(1996)\end{array}$ & & & & & & & & & & & & & & $\mathrm{x}$ & & & & $\mathrm{x}$ & $\mathrm{x}$ & $\mathrm{x}$ & & & & & & $\mathrm{x}$ \\
\hline $\begin{array}{c}\text { Callan \& Fearon } \\
(1997)\end{array}$ & & & & & & & $\mathrm{x}$ & & & & & & & & & & & $\mathrm{x}$ & $\mathrm{x}$ & & & & $\mathrm{x}$ & & & $\mathrm{x}$ \\
\hline $\begin{array}{c}\text { Chuah, Hua \& Ping } \\
\text { (1998) }\end{array}$ & & & & & & & & & & & & & & & & & & & & $\mathrm{x}$ & & $\mathrm{x}$ & & & & $\mathrm{x}$ \\
\hline $\begin{array}{c}\text { Rutes ve diğ. } \\
(2001)\end{array}$ & & & & & & & & & & & & & $\mathrm{x}$ & $\mathrm{x}$ & $\mathrm{x}$ & $\mathrm{x}$ & $\mathrm{x}$ & & $\mathrm{x}$ & $\mathrm{x}$ & & $\mathrm{x}$ & & & & $\mathrm{x}$ \\
\hline $\begin{array}{l}\text { Freund de Klumbis } \\
(2002)\end{array}$ & & & & & $\mathrm{x}$ & & $\mathrm{x}$ & $\mathrm{x}$ & & & & & & & & & & $\mathrm{x}$ & $\mathrm{x}$ & & & $\mathrm{x}$ & & & & \\
\hline $\begin{array}{c}\text { Mcintosh \& Siggs } \\
(2005)\end{array}$ & & & & & & $\mathrm{x}$ & & & & & $\mathrm{x}$ & & & & & & & & & $\mathrm{x}$ & $\mathrm{x}$ & & & & & $\mathrm{x}$ \\
\hline Aggett (2007) & & & & $\mathrm{x}$ & & & & & & & $\mathrm{x}$ & & & & & & & & & $\mathrm{x}$ & & & $\mathrm{x}$ & & & $\mathrm{x}$ \\
\hline $\begin{array}{c}\text { Lim \& Endean } \\
(2009)\end{array}$ & & & & & & & $\mathrm{x}$ & & & & & $\mathrm{x}$ & & & & & & $\mathrm{X}$ & $\mathrm{x}$ & $\mathrm{x}$ & & & & $\mathrm{x}$ & & $\mathrm{x}$ \\
\hline Olga, (2009) & & & & & & & $\mathrm{x}$ & & $\mathrm{x}$ & & & $\mathrm{x}$ & & & & & $\mathrm{x}$ & & & & & $\mathrm{x}$ & & & & \\
\hline $\begin{array}{c}\text { Rogerson \& Kotze } \\
(2011)\end{array}$ & & & & & & & & & $\mathrm{x}$ & & & & & & & & & & & & & & & & & \\
\hline $\begin{array}{c}\text { Balekjian ve } \\
\text { Sarheim (2011) }\end{array}$ & $\mathrm{x}$ & $\mathrm{X}$ & $\mathrm{X}$ & & & & & & & $\mathrm{x}$ & & & & & & & & & & & & & & & $\mathrm{x}$ & $\mathrm{x}$ \\
\hline Jones ve diğ. (2013) & $\mathrm{x}$ & & & & $\mathrm{x}$ & & & & & & & & & & & & & $\mathrm{x}$ & & & & & $\mathrm{x}$ & & & \\
\hline $\begin{array}{c}\text { Kavramların siklık } \\
\text { değerleri }\end{array}$ & 2 & 1 & 1 & 1 & 2 & 2 & 4 & 1 & 3 & 1 & 2 & 2 & 1 & 2 & 1 & 1 & 2 & 4 & 5 & 6 & 1 & 4 & 3 & 1 & 1 & 8 \\
\hline
\end{tabular}


Elde edilen kavramsal veri sayısallaştırılmış ve değerlendirilmiştir. Böylece butik oteli tanımlama yaklaşımlarından yola çıkarak butik oteli karakterize eden unsurlar belirlenmeye çalışılmıştır.

Ulaşılan bulgulara göre, 26 farklı kavramın butik oteli tanımlamada kullanıldığı, 2000 yılı öncesi yayınlarda ağırlıklı olarak işletme yapısı, büyüklüğü ve sunulan hizmetle ilişkili kavramların tanımlamada yer aldığı, sonraki dönemlerde mimari tasarım ve dekorasyon unsurlarının tanıma dahil edildiği görülmektedir. Tanımlarda en sık karşılaşılan kavramlar sırasıyla kişiye özel servis, lokasyon, işletme şekli, işletme büyüklüğü, tasarım ve dekorasyon tarzı ile hitap ettiği müşteri kitlesidir. Bu kavramlar bir konaklama ünitesini butik otel olarak tanımlayan, butik otelin karakterini biçimlendiren olmazsa olmaz unsurların altını çizmektedir. Tanımlarda mimari ve dekorasyon tarzıyla ilişkili kavramların sayısal olarak daha fazla kullanıldığı görülmektedir. Bu bulgu; butik otelin özgün karakterinin biçimlenmesinde mimari yapının ve dekorasyon tarzının ne denli önemli olduğuna vurgu yapar
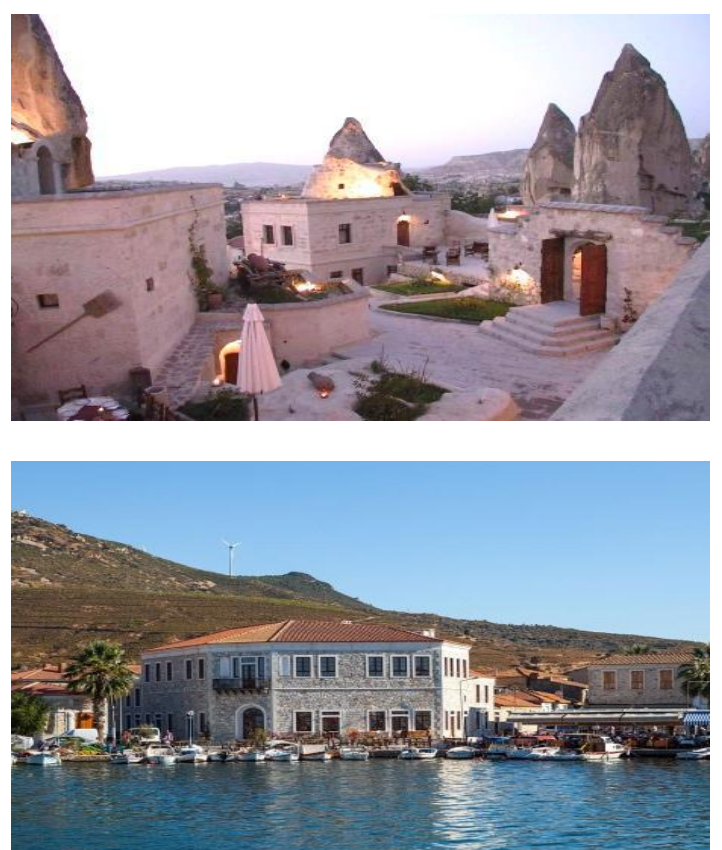

niteliktedir. Tanımlayıcı karakteristiğin geliştirilebilmesi için ise tespit edilen 26 farklı kavramın işaret ettiği ortak ögelerin belirlenerek gruplanmasına gerek duyulmuştur. Yapılan gruplama sonucunda; mimari ve dekorasyon tarz1, yapının elde edilme şekli, büyüklük, oda sayısı ve hizmet kapasitesi, işletme yapısı, lokasyon, misafir profili, konaklama şekli ve sunulan hizmetler olmak üzere butik oteli karakterize eden ve sıradan bir konaklama ünitesinden ayıran yedi ana unsur olduğu belirlenmiştir. Belirlenen unsurlar literatür bilgisine dayanarak açıklanmaya çalışılacaktır.

\subsection{Lokasyon}

Butik konaklamayı özelleştiren unsurlar sunulan konforlu ortam ve şı k atmosferle sınırlı olmayıp, yapının içinde yer aldığı yakın çevreye ait nitelikler butik karakterin önemli bir parçasıdır [10]. Butik oteller kırsaldan kent merkezine dek özellikli her lokasyonda bulunabilir, lokasyon butik otelin karakterini biçimlendirir ve gezgin profiline bağlı olarak lokasyon tercihi belirir (Şekil 2), [13, 15, 21].
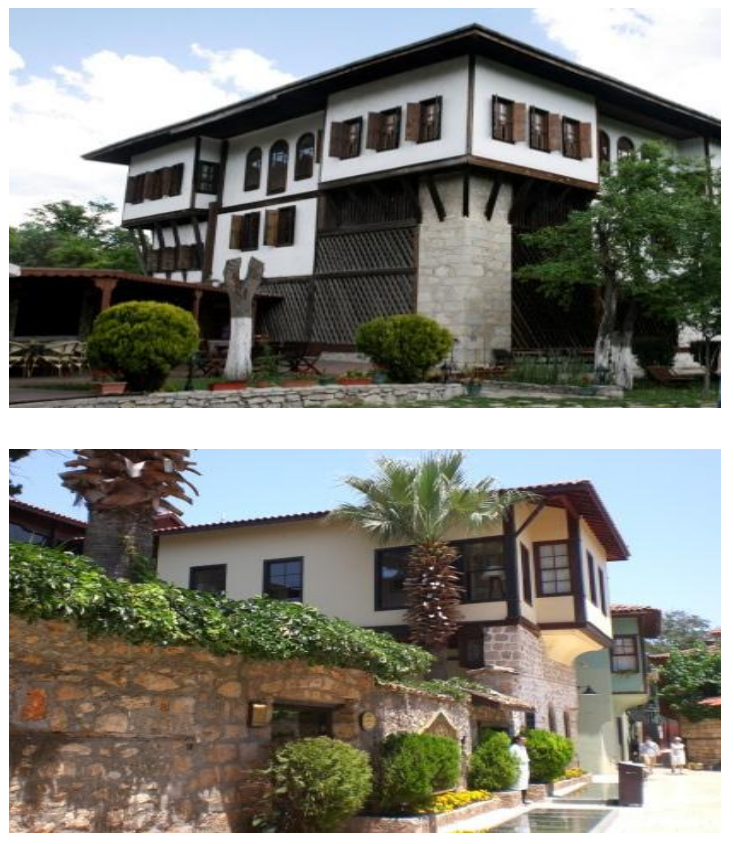

Şekil 2. Lokasyona bağlı olarak yöre kültürüyle farklılaşan butik otel karakterine ülkemizden örnekler (URL5-URL8) 
Butik oteller lokasyona göre kent içi ve sayfiye butik oteller olarak iki gruba ayrılabilir [21]. Daha bilinmedik, herkesten uzak, gizli kalmış sayfiye yerlerine ulaşım, merkezi lokasyonlara göre daha zor olmakla birlikte, sıradan insanların bilmediği bir yerde olma hissi konaklayanın kendini çok daha özel ve ayrıcalıklı hissetmesine neden olur.

Turizmin çeşitlenmesi, konaklayanların yeni deneyimler yaşama istekleri ve ayrıcalıklı olma durumu ulaşım zor da olsa, sayfiyedeki tesislere talebin artışına sebep olarak gösterilmektedir [22]. Sayfiye butik otelleri daha küçük, samimi ve egzotik olmanın yanında yerel çevrenin özelliklerini taşıyan geleneksel mimari ve yöresel karakteri, lüks ve konforla birleştiren yapılar olarak tariflenir. Kent içi butik oteller ise kentin alışveriş bölgesi, tarihi turistik merkezi ya da seçkin konut yerleşiminin olduğu, canlı, yaşayan noktalarında yer alan, tarihi-geleneksel ve modern unsurların harmanlandığı, tarz sahibi, tasarım yapılar olarak tanımlanır [21].

Butik otellerin tercihinde lokasyon değerinin; yöre kültürünün etkisi ve konaklayanların yaşantıyı deneyimleme arzusuna paralel olarak arttığ görülmektedir [2]. Bu doğrultuda yöresel yaşam kültürünü yansıtan geleneksel yapıların orijinal biçimi, işlevi ve mimari özellikleri konaklayanlar tarafından yaşantının deneyimlenmesi için ideal bulunmaktadır. Bunun sonucunda, her yörenin kendine has nitelikleriyle biçimlenmiş, farklı karakterde çok çeşitli butik otellere rastlamak mümkündür. Farklılıkta görülen çeşitlilik butik otellerin lokasyon değerini olumlu etkiler.

\subsection{Yapının Elde Edilme Şekli}

Tanımlama yaklaşımları incelendiğinde butik otellerin dönüştürülerek veya inşa edilerek elde edildiği söylenebilir. Ancak inşa edilerek elde edilen yeni yap1 örnekleri dönüşümle elde edilenlere oranla daha azdır [13]. Daha çok geleneksel ya da tarihi değere sahip ve esas işlevin konut olduğu yapılar dönüştürülmekle birlikte, han, ofis yapısı, katlı mağaza, su deposu gibi konut dışı işlevlerden dönüşüm örneklerine rastlamak mümkündür [3, 5], (Şekil 3). Ayrıca ülkemizde Merkez bankası İzmir Şubesinin butik otele dönüştürülmesi örneğinde olduğu gibi yakın dönem yapılarının dönüştürüldüğü örnekler son zamanlarda görülmeye başlanmıştır [1].

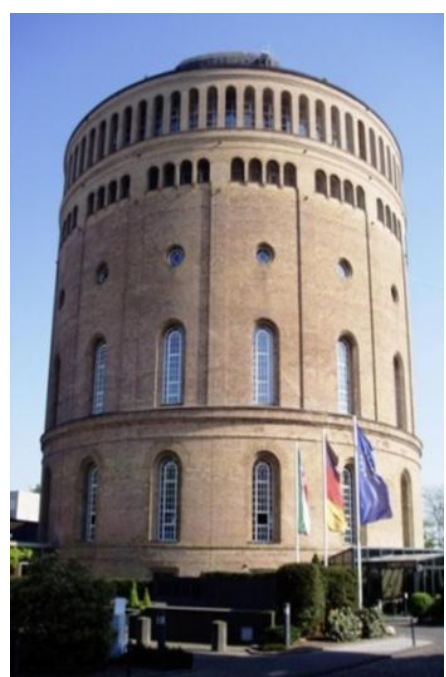

Su kulesinden dönüştürülen Hotel im Wasserturm, Köln, (URL2)

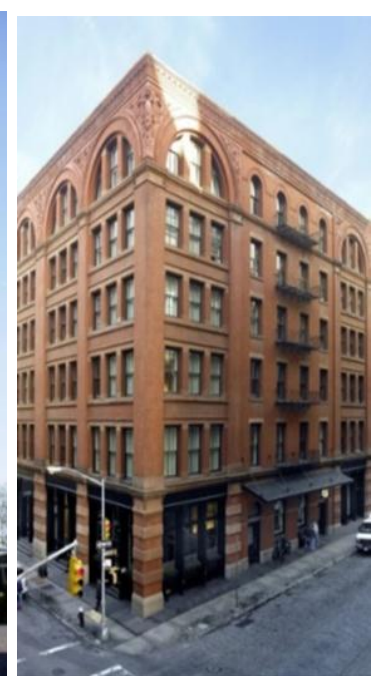

Çok katlı mağazadan dönüştürülen The Mercer Hotel, New York, (URL3)

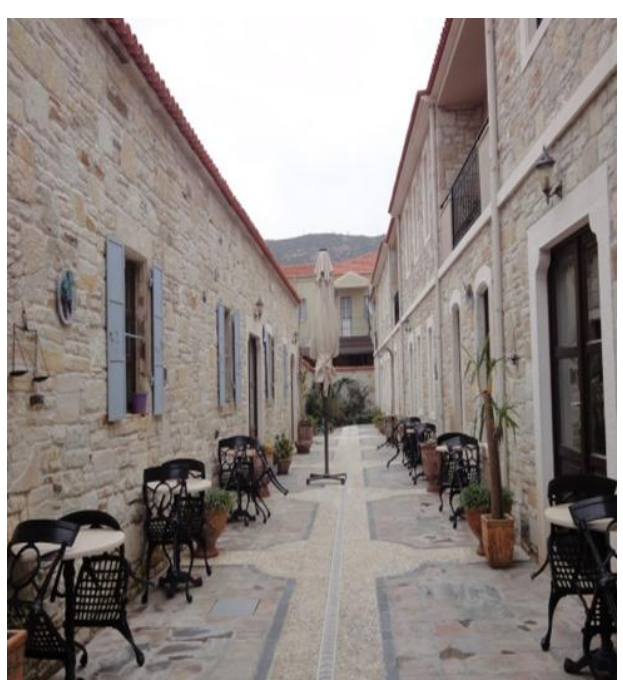

Zeytinyağı fabrikasından dönüştürülen Griffon Otel, Foça, (URL4)

Şekil 3. Farklı işlevsel orijinli yapılardan dönüşüm örnekleri 
Kültürel ve tarihi değeri olan geleneksel yapılardan dönüştürülen örnekler sunulan konaklama deneyimi bakımından cazip bulunmasına rağmen, dönüştürme sirasında birtakım sorunlarla karşılaşılmaktadır. Yapının mevcut olanaklarıyla tasarım programını karşılamada yetersiz kalması ve yenileme sirasinda uyulması gereken yasal zorunluluklar karşılaşılan en önemli sorunlar arasında sayılabilir [2].

\subsection{Mimari ve Dekorasyon Tarzı}

Butik otel konsepti içinde mimari tarz ve dekorasyon gelenekselden moderne ulaşan yelpaze içinde çeşitlenmektedir. Göz kamaştırıcı, zarif, tarz sahibi, şık ve moda gibi kavramların tanımlamada kullanılması butik otel konsepti içinde mimari tarzın ve dekorasyonun öneminin altını çizmektedir [3]. Mimari ve dekorasyon tarz1, konaklayanın unutulmaz bir deneyim yaşamasını sağlayan atmosferi ve ambiyansı yaratması nedeniyle butik konaklamayla adeta bütünleşmiştir.

$\mathrm{Bu}$ iki konuya sektörde verilen önem Anouska Hempel ve Alexandra Champalimaud'un dekorasyonunu tasarladikları otellerle özdeşleşmesi ve konaklama sektöründe günümüzün marka tasarımcıları haline gelmesiyle anlaşılabilir (Şekil 4).
Mimari ve dekorasyon tarzına göre butik oteller üçe ayırılabilir (Şekil 5) [2].

a) Geneksel Butik Otel: Mimarisi tamamen geleneksel tarzdadır, dekorasyon lüks geleneksel mobilyalar ile tamamlanmıştır. Yöre kültürünü yansıtan özellikler taşır.

b) Geleneksel-Modern Butik Otel: Geleneksel mimari, modern dekorasyon ya da modern mimari ve geleneksel dekorasyonun zarif bir karışımıdır. Yöre kültürü mimari veya dekorasyon ögelerinde yer alır.

c) Modern Butik Otel: Mimarisi ve dekorasyonu tamamen modern olan butik otel otellerdir.

\subsection{Büyüklük, Oda Sayısı ve Hizmet Kapasitesi}

Butik otel kavramı küçük olmakla özdeşleştirilir ve çoğu tanımda ev gibi, aile ortamı gibi şeklindeki ifadeler bir yandan otel yapısının büyüklüğüne işaret ederken, diğer yandan hizmet kapasitesi ve hizmet sunumuna vurgu yapar. Ancak literatürde büyüklüğe ilişkin farklı görüşler mevcuttur. Literatürde küçük olmaya özellikle vurgu yapılmakla birlikte 50'nin altında, 50-100 arasinda, 150'den az veya150-200 arasinda gibi farklı oda sayılarına rastlanır $[10,11,15,23,24]$.

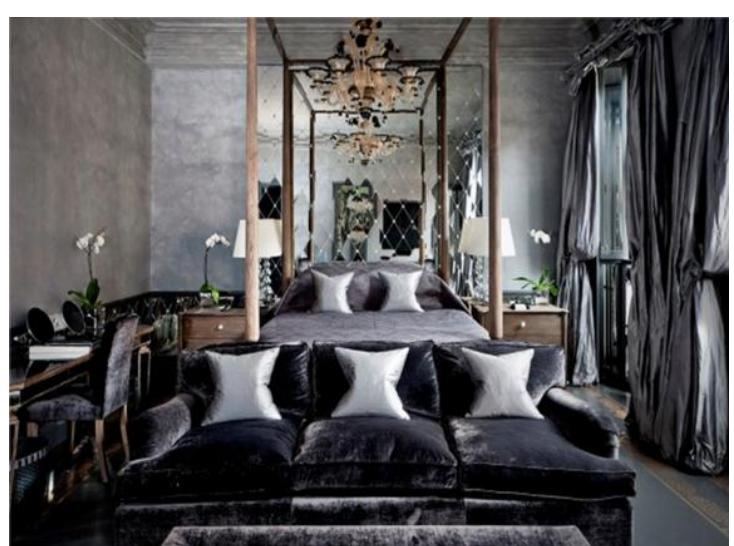

a) Blake's Hotel, Londra, (URL9)

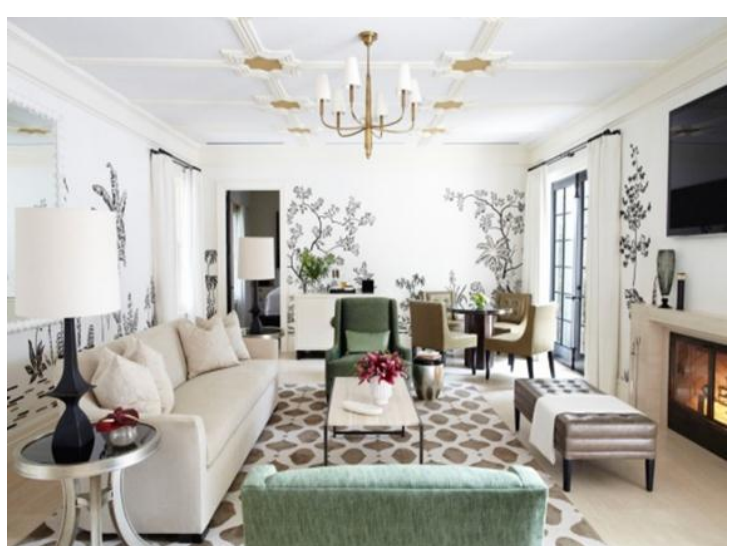

b) Bel Air Hotel, Kaliforniya, (URL10).

Şekil 4. Anouska Hempel (a) ve Alexandra Champalimaud'un (b) butik otel odası tasarımlarından örnekler 

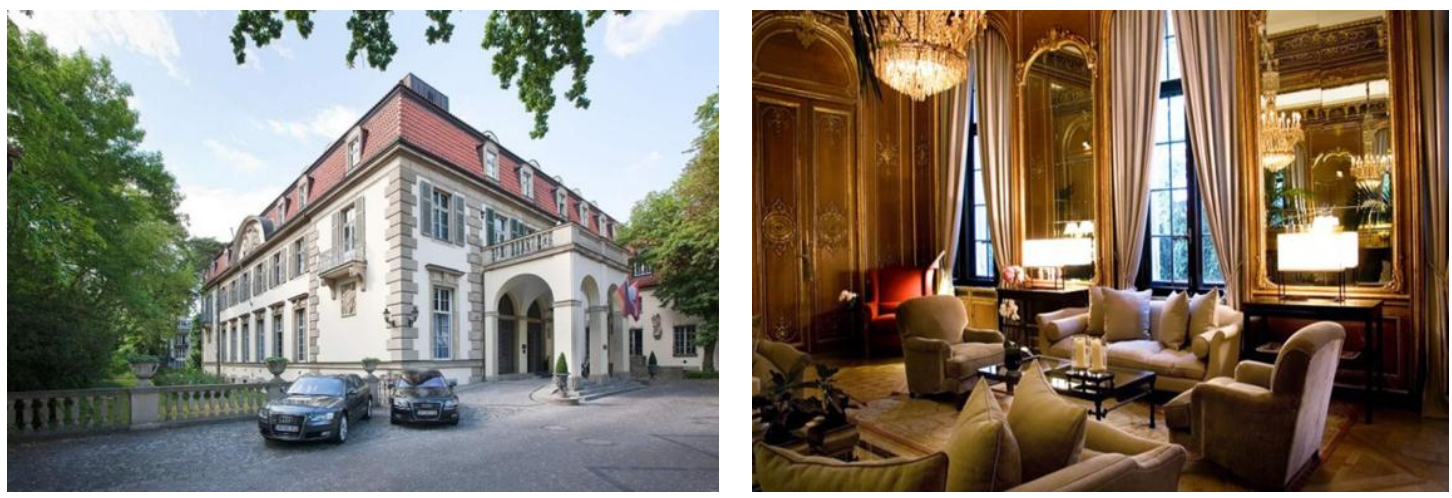

a) Geneksel butik otel örneği, (URL11)
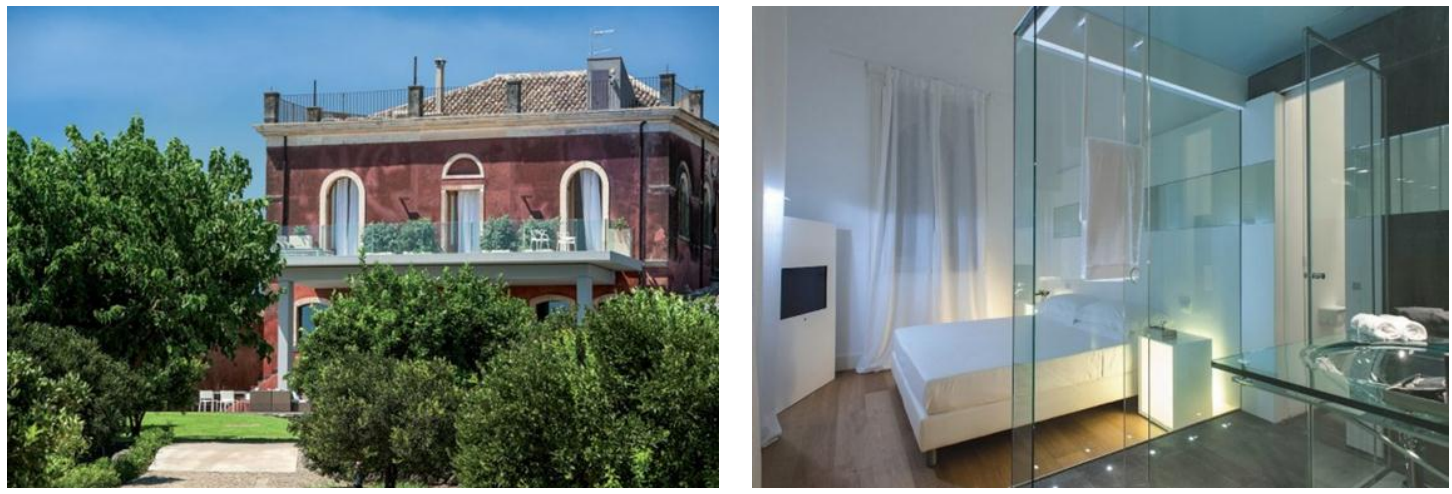

b) Geleneksel-modern butik otel örneği, (URL12)
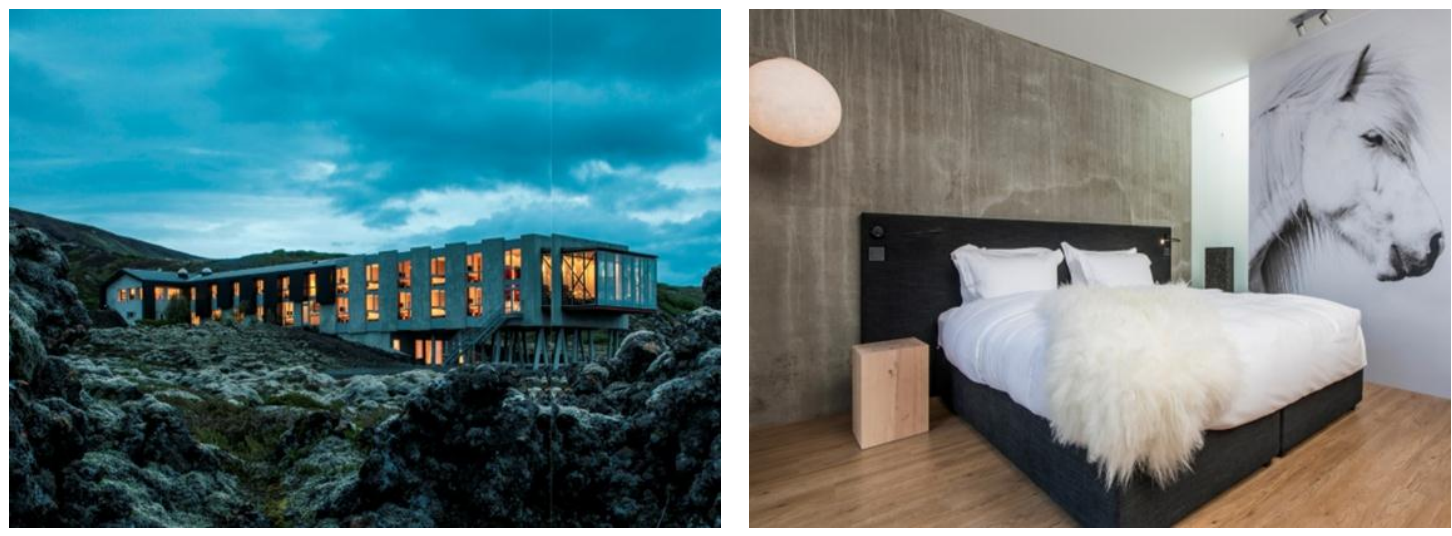

c) Modern butik otel örneği, (URL13).

Şekil 5. Mimari ve dekorasyon tarzına göre butik otel örnekleri 


\subsection{Büyüklük, Oda Sayısı ve Hizmet Kapasitesi}

Butik otel kavramı küçük olmakla özdeşleștirilir ve çoğu tanımda ev gibi, aile ortamı gibi şeklindeki ifadeler bir yandan otel yapısının büyüklüğüne işaret ederken, diğer yandan hizmet kapasitesi ve hizmet sunumuna vurgu yapar. Ancak literatürde büyüklüğe ilişkin farklı görüşler mevcuttur. Literatürde küçük olmaya özellikle vurgu yapılmakla birlikte 50'nin altında, 50-100 arasinda, 150 'den az veya150-200 arasında gibi farklı oda sayılarına rastlanır $[10,11,15,23,24]$. Oda sayısı konusunda otelin lokasyonu, yapının elde edilme şekli ve işletme yapısı belirleyicidir. Avrupa'da daha çok dönüştürülmüş, tarihi merkezde, küçük ölçekli aile işletmesi olarak hizmet veren butik oteller ortalama 86 oda sayısına sahipken Amerika'da kent merkezinde, inşa edilerek veya dönüşümle elde edilmiş ve aile işletmesinden çok zincir işletme olarak hizmet veren butik otellerde 700-1000 oda sayısından söz etmek mümkündür [3, 25]. Ancak küçük, kendine has olmanın ve kişiye özel hizmetin öne çıkarıldığ butik otellerde 700-1000 odalı bir işletmenin butik olma durumu çelişkiler taşımaktadır. Zincir işletmelerin sektöre girmesiyle oluştuğu sanılan aşırı büyüklük durumunun gelecekte butik otelleri zincir işletmeler altında tipleşen, özgün karakterini kaybederek standardize edilmiş konaklama yapılarına dönüştürebileceği düşünülmektedir.

\subsection{Konaklama Şekli ve Sunulan Hizmetler}

Butik konaklama bütünüyle özel bir deneyimdir ve sunulan kişiye özel hizmetle kendine has bir karaktere sahip olur. Butik otel konaklamasının tercih edilmesinde; sunulan hizmetin kişiselleştirilmiş veya kişisel dokunuşlara sahip olması, konaklarken evde olma hissi uyandırması, yüksek kalite standartlarında hizmet sunulması önemli birer faktördür [4, 8, 18]. Kişiye özel hizmet kavramının üst sınırı yoktur ve lüks değeri arttıkça kişisel hizmetin çeşitliliği artar. Butik otellerde sunulan hizmetin kalitesinin; konaklama kapasitesi ve personel sayısı ile ilişkili olduğu, hizmet kapasitesinin, otel büyüklüğü ve çalışan sayısı ile dengeli bir büyüklükte olması gerektiğgi söylenebilir. Bunun yanında dekorasyon tarzı ve odaların döşenme şekli kullanıcıların kısa vadeli kullanımına uygun, konaklamaya ait özel deneyimi yaşamasını sağlar nitelikte olmalıdır [26]. Ayrıca iletişim ve medya teknolojilerini içeren olanaklar konaklamada konfor hissini etkilemesi bakımından sunulan hizmetler arasında dikkate alınabilir [2].

\section{6. İşletme Yapısı}

Butik oteller pek çok tanımlama yaklaşımında küçük olmakla karakterize edilerek, bu yapıların genellikle sahipleri tarafindan işletildiği ve zincir otel ya da global işletmeler bünyesinde yer almadığ 1 belirtilir $[7,9,11,13]$. Butik otellerin küçük olması ve özellikle sahibi tarafından işletilmesi, kişiye özel hizmet kapsamında müşteriyle birebir ilişkiyi desteklemesi açısından önemli bulunmaktadır [15]. Ancak butik konaklamanın sektörde hızla gelişimi global işletmelerin dikkatini çekmiş ve son yıllarda bu işletmeler kendi markaları altında zincir butik otelleri hizmete açmaya başlamıştır [6]. Zincir işletmelerin sektörde yer almasının etkileri büyüklük, oda sayısı ve hizmet kapasitesi kısmında tartışılmaya çalışılmıştır.

\subsection{Misafir Profili}

Demografik yapının değişimi, yüksek gelirli, eğitimli, tarih ve kültürle ilgili grubun artmasının konaklamayla dair beklentilerin değişimine neden olduğu, bunu izleyen süreçte yeni gezgin grubunun taleplerinin butik otellerin gelişmesini etkilediği vurgulanmıştı. 20-50 yaş aralığındaki yüksek sosyo-kültürel ve sosyo-ekonomik değere sahip elit gezgin grubu, kendini farklı hissetmesini sağlayacak, standardın ve alışılagelmişin dışında, kimsenin bilmediği yerlerde, kişisel gelişimine zenginlik katacak deneyim arayışı içindedir $[8,10]$. Deneyim orada olmaktan çok gidilen yeri yaşamak, günlük hayatı deneyimlemek ve oralı gibi olmaktır. Gezgin grubunun profilinin, lokasyon seçimi ve mimari karakterin biçimlenmesine ilişkin kararları etkileyeceği ve bu bakımdan önemli olduğu düşünülmektedir.

\section{SONUÇ}

Özellikle zincir otellerin sunduğu standart konaklamaya bir tepki olarak ortaya çıtı̆̆ 1 
belirtilen butik oteller toplumsal yapının değişmesi, gezgin grubunun seyahat ve tatil beklentisinin farklılaşmasıyla hızla yayılım ve sayısal gelişim göstermiştir. İlk örneklerinin Avrupa'da görüldüğü ve şehir evi oteli ya da cazibe oteli olarak adlandırıldığı bu küçük oteller Morgans ile birlikte "butik" olarak tanımlanmaya başlanmıştır. Butik otellerin sunduğu hizmet kalitesi ve tatil deneyimi ile bütünleşen mimari karakteri, standart konaklamaya karşı ortaya çıkışının en önemli göstergesi olarak dikkate alınabilir.

Butik oteller hizmet sunumunda çok fazla çeşitliliğe ve değişkene, büyüklüğe ve kapasiteye, kendine özgü mimari tarz ve dekorasyon ile lokasyon değerine sahiptir. Tasarlanıp inşa edilerek veya farklı işlevsel orijinlerden dönüştürülerek elde edilen bu konaklama yapıları sundukları konaklama deneyimi ile ayrıca farklılaşır. Tüm bunların bir sonucu olarak butik otellerin genel geçer bir tanımını yapmanın olanaklı olmadığı görülmektedir. Öte yandan standart olana karşı gelişen bir olgunun standart bir tanımla ifade edilmesinin doğal olarak beklenemeyeceği düşünülmektedir. Ancak araştırmada ulaşılan nokta; butik otellerin küçük, kişisel hizmet sunan, özgün ve farklı tasarıma sahip şık konaklama üniteleri olduğudur. Her butik otel kendine özgüdür ve butik otellerin en büyük benzerliği deneyime dayanması ve kişiye özel sunulan kaliteli hizmettir.

Ülkemizdeki duruma bakıldığında ise butik otellerin yönetmelikle tanımlandığı ve işletme yapisinin bu anlamda standardize edilmeye çalışıldığı görülür. Turizm potansiyeliyle öne çıkan ülkemizde her yörede farklı bir karaktere bürünen butik otellerin sayısı azımsanmayacak düzeydedir. Ancak; pek çok işletmenin butik otel işletme belgesine sahip olmadığı halde "butik otel" adı altında hizmet vermesi farklı yönlerden yoruma açık bir bulgudur. Bu bulgu ilk anda belgesiz butik otel işletmelerinin "butik" etiketini diğerlerinden ayıran kalite unsuru olarak kullandığı şeklinde yorumlanabilir. Diğer bakımdan ise bu bulgunun; gerçek anlamda butik hizmet veren fakat butik otel işletme belgesi olmayan bu otellerin gösterdikleri çeşitlilik ile yönetmelik sınırları içinde standardize edilmesindeki zorluğu işaret ettiği düşünülmektedir.

Çalışma mevcut tanımlama yaklaşımlarını irdeleyerek butik otellere özgü tanımlama kriterlerini geliştirmeye çalışmıştır. Butik oteli tanımlamada kullanılan 26 farklı kavram içeriklerine göre gruplanarak, bir konaklama yapısını "butik" yapan karakteristik unsurlar tespit edilmiştir. Sonuç olarak; lokasyon, yapının elde edilme şekli, mimari ve dekorasyon tarzı, büyüklük, oda sayısı ve hizmet kapasitesi, konaklama şekli ve sunulan hizmetler, işletme yapısı ve misafir profili olmak üzere yedi kriter elde edilmiştir. Belirlenen kriterlerin, kesin bir tanımlama yapmak yerine geniş alt açılımlarıyla, butik otel kavramı için betimleyici çerçevenin çizilmesini sağladığı söylenebilir.

\section{TEŞEKKÜR}

Bu çalışma, Çukurova Üniversitesi BAP Birimi tarafindan FYL-2014-1973 Proje kodu ile desteklenmiştir.

\section{KAYNAKLAR}

1. Erman, O., 2013. Turizm ve Mimarlık, Güney Mimarlık, TMMOB Mimarlar Odası Adana Şubesi Yayını, Sayı:2013/12, s.17-18.

2. Can, E., 2014. Kullanıcı Beklentilerinin Butik Otel Tasarımına Etkisinin Değerlendirilmesi, Yayımlanmamış Yüksek Lisans Tezi, Ç.Ü. Fen Bilimleri Enstitüsü, Mimarlık ABD., Adana.

3. Rutes, W., Penner, R., Adams, L., 2001. Hotel Design, Planning, and Development. WW Norton \& Company New York.

4. Aggett, M., 2007. What has İnfluenced Growth in the UK's Boutique Hotel Sector?, International Journal of Contemporary Hospitality Management, Cilt:19, Say1:2, s.169-177.

5. Miller, J., 2001. Personality Equals Popularityand Profits- at Boutiques, National Real Estate Investor, Cilt:43, Say1:10, s.90-92.

6. Jones, D. L., Day, J., Quadri-Felitti, D., 2013. Emerging Definitions of Boutique and Lifestyle Hotels: A Delphi Study, Journal of 
Travel \& Tourism Marketing, Cilt:30, Say1:7, s.715-731.

7. Morrison, A. M., Pearce P. L., Moscardo, G., Nadkarni, N., O'Leary, J. T., 1996. Specialist Accommodation: Definition, Markets Served, and Roles in Tourism Development, Journal of Travel Research, Cilt35, Say1:1, s.18-26 .

8. Munsters, W., Freund de Klumbis, D., 2005. Culture as a Component of the Hospitality product, Eds.: D. Leslie ve M. Sigala, International Cultural Tourism, ButterworthHeinemann, Elsevier, s.26-39.

9. Callan, R., Fearon, R., 1997. Town House Hotels-An Emerging Sector. International Journal of Contemporary Hospitality Management, Cilt:9, Say1:4, s.168-175.

10. Olga, A., 2009. The Alternative Hotel Market, 16th International Conference on Management Science \& Engineering (ICMSE), Moscow, s.2021-2025.

11. Freund de Klumbis, D., 2002. Seeking the Ultimate Hotel Experience, XII. International Leisure and Tourism Symposium (ESADE), Barcelona, http://www.esade.edu/cedit2003/pdfs/danielafr eund.pdf [Erişim:20.07.2014]

12. McNeill, D., McNamara, K., 2010. Cultural Economy of Boutique Hotel: The Case of the Schrager and W Hotels in New York, Eds.: M. K. Goodman, D. Goodman, M. R. Redclift, Surrey, Consuming Space Placing Consumption in Perspective, Ashgate Pub., Farnham, s.147-160.

13. Lim, W. M., Endean, M., 2009. Elucidating the Aesthetic and Operational Characteristics of UK Boutique Hotels, International Journal of Contemporary Hospitality Management, Cilt:21, Say1:1, s.38-51.

14. Christersdotter, M., 2005. Transformers. Hip Hotels and The cultural Economics of AuraProduction, Eds.: O. Lofgren ve R. Willim, Magic, Culture and the New Economy, Berg Publisher, Oxford, s.73-86.

15. Chuah, J. T. C., Hua, G. C. G., Ping, M. K. H., 1998. Size Really Does Matter (When You're Small): The Critical Success Factors Behind Boutique Hotels in Singapore, International Council For Small Business Conference (ICBS),

Singapore, http://www.sbaer.uca.edu/research/icsb/1998/1 01.pdf [Erişim:02.09.2014]

16. Khosravi, S., Yussof, I., Bahauddin, A., Mohamed, B., 2012. Potentials of Boutique Hotel: The Case of Penang Island, Malaysia, OIDA International Journal of Sustainable Development, Cilt:04, Sayı:08, s.71-78.

17. Balekjian, C., Sarheim, L., 2011. Boutique Hotels Segment-The Challenge of Standing Out from the Crowd", HVS International, Londra, http://www.hvs.com/Content/3171.pdf [Erişim:21.09.2014]

18. McIntosh, A. J., Siggs, A., 2005. An Exploration of the Experiential Nature of Boutique Accommodation, Journal of Travel Research, Cilt:44, Say1:1, s.74-81.

19. Rogerson, J.M., Kotze, N., 2011. Market Segmentation and the Changing South African Hotel Industry (1990 to 2010), African Journal of Business Management, Cilt:5, Sayı:35, s.13523-13533.

20. Turizm Tesislerinin Belgelendirilmesine ve Niteliklerine İlişkin Yönetmelik, 2005/8948, Resmi Gazete, http://www.resmigazete.gov.tr/eskiler/2005/06/ 20050621-11.htm [Erişim: 18.07.2014]

21. Anhar, L., 2001. The Definition of Boutique Hotels, HVS International, Londra, http://www.hospitalitynet.org/news/4010409.ht $\mathrm{ml}$ [Erişim:18.07.2014]

22. Bigne, J. E., Andreu, L., 2004. Emotions in Segmentation: An Empirical Study, Annals of Tourism Research, Cilt:31, Say1:3, s.682-696.

23. Drewer, P., 2005. Key Note Market report plus: Hotels, 20th edt. Key Note, Hampton.

24. Pearce, P. L., Moscardo, G. M., 1992. The Boutique/Specialist Accommodation Sector: Perceived Government Needs and Policy Initiatives, Queensland Small Business Research Journal, Say1:1, s.34-41.

25. Forsgren, S., Franchetti, C., 2005. The Marketing Role of Unique Concepts for Hotels in Sweden, Yayınlanmamış Yüksek Lisans tezi, Göteborg University, School of Economics and Commercial Law, Göteborg, http://hdl.handle.net/123456789/725

[Erişim:20.07.2014] 
26. Rabontu, C. I., Niculescu, G., 2009. Boutique Hotels-New Appearances in Hotel Industry in Romania, Economics, Cilt:9, Sayı:2, s.209-214.

\section{Görsel Kaynakçası}

URL1: http://www.eleganceeasthotel.com/\#1

URL2:http://upload.wikimedia.org/wikipedia/com mons/5/51/Koeln_Hotel_im_Wasserturm.jpg

URL3:http://cdnx.jetcdn.com/static/dimg/rlWgMK EuMTS0LFV6rlWmnKcyVwc7VaqcMUEbV wb3ZmHfVzuynJqbqPV6ZGRjZa19YPWjLK EbVwbvnJ1uM2ImY3Olo2E1L3DipUWipTIlq Tyyp181Zwx3 Y3Olo3NgZmpkAQxgZGZmAG D2AGV5AP1mpzZhnaOaVvjvqzIlp2yiovV6V vW9

URL4:http://www.restorasyonforum.com/restorasy on-oncesi-sonrasi/eski-zeytinyagifabrikasigriffon-butik-otel-t7172.0.html

URL5:http://www.cornucopia.net/library/guide/Ho tels/CCS.jpg

URL6:http://www.gokcuoglukonagi.com/tr/imgdemo/gallery/gk/index.html\#!prettyphoto[galle ry1]/10/

URL7: http://www.lapetraotel.com/gallery.php

URL8: http://www.alppasa.com/galeri/

URL9: http://www.blakeshotels.com/gallery

URL10:http://champalimauddesign.com/projects/h otels/the-hotel-bel-air.aspx

URL11: http://schlosshotelberlin.com/

URL12: http://www.zash.it/

URL13: http://ioniceland.is/ 
